\title{
Parallel Processing of Nociceptive A- $\delta$ Inputs in SII and Midcingulate Cortex in Humans
}

\author{
Maud Frot, ${ }^{1,2}$ François Mauguière, ${ }^{1,2,3}$ Michel Magnin, ${ }^{1,2}$ and Luis Garcia-Larrea ${ }^{1,2}$

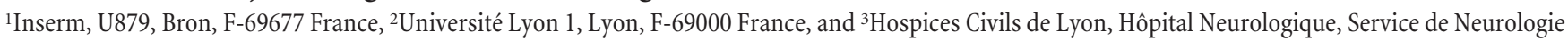 \\ Fonctionnelle et d'Epileptologie, Bron, F-69677 France
}

The cingulate cortex (CC) as a part of the "medial" pain subsystem is generally assumed to be involved in the affective and/or cognitive dimensions of pain processing, which are viewed as relatively slow processes compared with the sensory-discriminative pain coding by the lateral second somatosensory area (SII)-insular cortex. The present study aimed at characterizing the location and timing of the CC evoked responses during the $1 \mathrm{~s}$ period after a painful laser stimulus, by exploring the whole rostrocaudal extent of this cortical area using intracortical recordings in humans. Only a restricted area in the median CC region responded to painful stimulation, namely the posterior midcingulate cortex (pMCC), the location of which is consistent with the so-called "motor CC" in monkeys. Cingulate pain responses showed two components, of which the earliest peaked at latencies similar to those obtained in SII. These data provide direct evidence that activations underlying the processing of nociceptive information can occur simultaneously in the "medial" and "lateral" subsystems. The existence of short-latency pMCC responses to pain further indicates that the "medial pain system" is not devoted exclusively to the processing of emotional information, but is also involved in fast attentional orienting and motor withdrawal responses to pain inputs. These functions are, not surprisingly, conducted in parallel with pain intensity coding and stimulus localization specifically subserved by the sensory-discriminative "lateral" pain system.

Key words: cingulate; SII cortex; pain; evoked potentials; intracerebral recordings; YAP laser

\section{Introduction}

The cingulate cortex (CC) is a critical area for the cortical processing of nociceptive inputs. Its anterior and supracallosal part (Brodmann's area 24) receives direct afferent fibers from several thalamic nuclei (midline, intralaminar, and mediodorsal nuclei) involved in pain and limbic circuitry (Vogt, 2005). Numerous functional neuroimaging studies have shown that the midcingulate cortex (MCC), one of the CC anatomical subdivisions proposed by Vogt et al. (1993, 2005), is activated by pain stimuli almost as consistently as the operculoinsular cortex [for review, see Peyron et al. (2000) and Jones et al. (2002)]. Moreover, pain responsive neurons have been identified by microelectrode exploration of the human brain in this cingulate area (Hutchinson et al., 1999). The neuroanatomical basis of pain has been conceptualized as involving "lateral" and "medial" subsystems (AlbeFessard et al., 1985). The "lateral" system (including thalamocortical afferents to SI, SII, and posterior insula) subserves the sensory-discriminative processing of pain inputs, whereas the "medial" system (with projections to the anterior cingulate and prefrontal cortices) would be preferentially involved in the mo-

Received June 28, 2007; revised 0ct. 1, 2007; accepted 0ct. 29, 2007.

This work was supported by grants of European Federation of Chapters of the International Association for the Study of Pain Grunenthal. We thank Dr. M. Guenot (Department of Functional Neurosurgery) for stereotactic electrode implantation and Dr. J. Isnard for useful discussions on these data. Thanks also to Drs. C. Fischer and P. Ryvlin for the opportunity to study their patients.

Correspondence should be addressed to Maud Frot, Inserm U879, Hôpital Neurologique, 59 Boulevard Pinel, 69677 Bron Cedex, France. E-mail: maud.frot@univ-lyon1.fr.

DOI:10.1523/JNEUROSCI.2934-07.2008

Copyright $\odot 2008$ Society for Neuroscience $\quad$ 0270-6474/08/280944-09\$15.00/0 tor, cognitive/evaluative, and emotional pain components. Although pain electrophysiological and imaging studies have revealed activation of cortical structures belonging to both the medial and lateral subsystems, there is robust clinical and physiological evidence that the two subsystems are implicated in different aspects of the pain experience (Rainville et al., 1997; Peyron et al., 1999; Hofbauer et al., 2001; Kulkarni et al., 2005), including clinical reports showing dissociation between sensory and affective pain components by discrete lesions in the medial (Foltz and White, 1962) or lateral pain systems (Ploner et al., 1999).

Although the anterior and middle cingulate portions are consistently activated by pain, the precise location of the areas involved shows non-negligible variations across blood flow-based imaging studies. Most of the activated areas are located in MCC, but they often spread to regions rostral or caudal to this area [for review, see Peyron et al. (2000) and Vogt (2005)]. In contrast, with only a few exceptions (Ploner et al., 2002; Bromm, 2004), source modeling of scalp laser-evoked potentials (LEPs) has consistently reported generators restricted to the posterior MCC (pMCC) (for review, see Garcia-Larrea et al., 2003). Source modeling is, however, hampered by the non-uniqueness of dipolar solutions and, despite a better time resolution than blood flowbased investigations, can be biased by interferences between brain generators that are concomitantly activated. This possibility is particularly relevant to LEPs because cingulate and operculoinsular activations occur in a narrow temporal window. To determine unambiguously the spatiotemporal characteristics of CC activation to pain, we studied responses in CC and suprasylvian 
Table 1. Coordinates (atlas of Talairach and Tournoux) of contacts (in millimeters) where the maximal amplitudes of the N/P deflection in bipolar mode were recorded in cingulate cortex and SII, for all patients

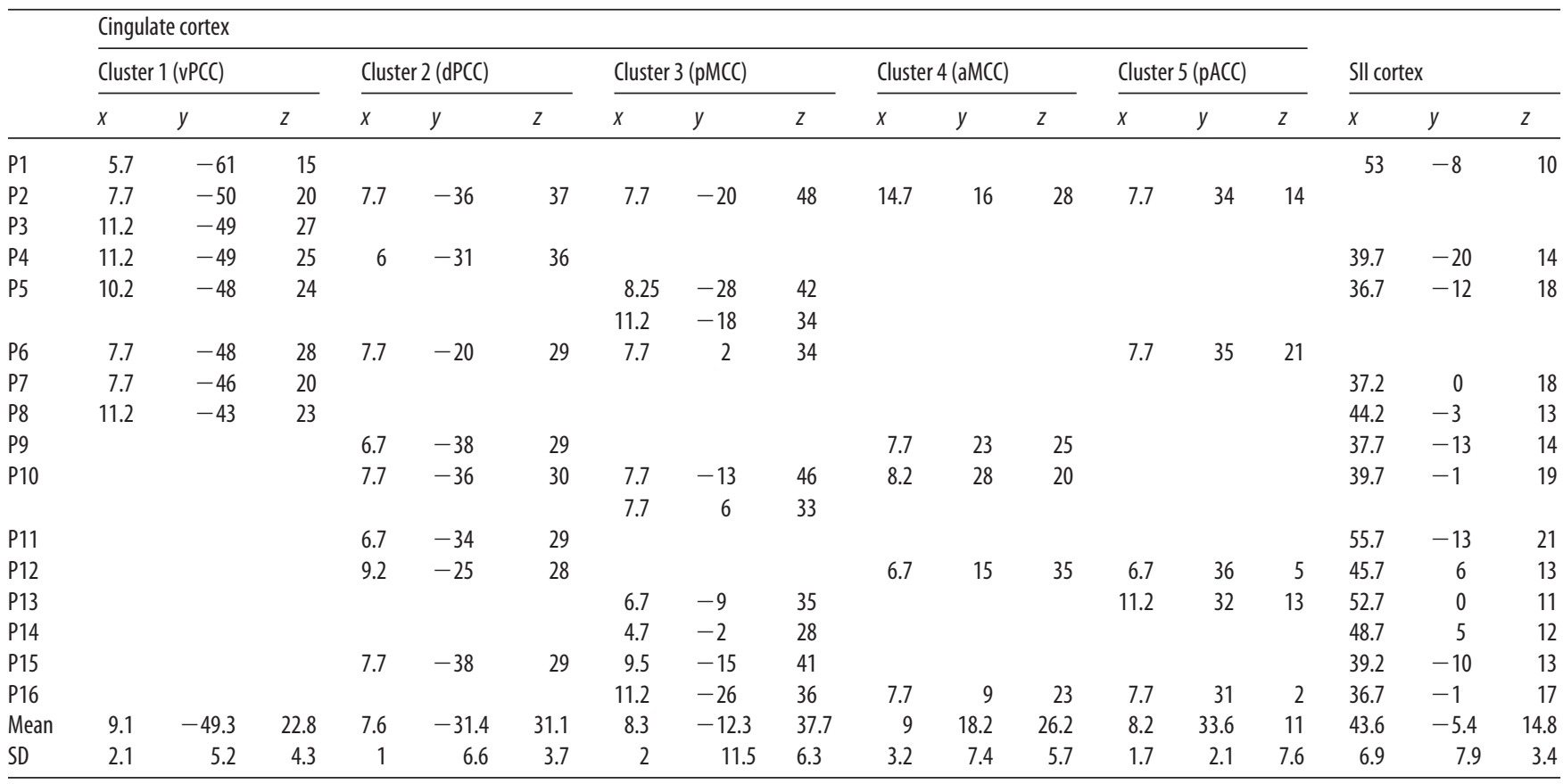

opercular cortex using intracerebral LEP recordings, which are ideally suited to assess accurately the dynamics of cerebral painevoked responses.

\section{Materials and Methods}

Patients. Eighteen patients were included in this study, all of whom suffered from partial refractory temporal lobe epilepsy and were investigated using stereotactically implanted intracerebral electrodes before functional neurosurgery. Among other sites, these patients had electrodes chronically implanted in the cingulate cortex and the second somatosensory area (SII) for the recording of their seizures. The decision to explore these areas resulted from the observation during scalp videoEEG recordings of ictal manifestations suggesting the possibility of seizures propagating to or originating from these regions (for a complete description of the rationale of electrode implantation, see Isnard et al., $2000,2004)$. This procedure, performed routinely before epilepsy surgery in patients implanted with depth electrodes, is completed by the functional mapping of potentially eloquent cortical areas using evoked potentials recordings and cortical electrical stimulation [for a description of the stimulation procedure, see Ostrowsky et al. (2002) and Mazzola et al. (2006)]. In agreement with French regulations relative to invasive investigations with a direct individual benefit, patients were fully informed about electrode implantation, stereotactic EEG (SEEG), evoked potential recordings, and cortical stimulation procedures used to localize the epileptogenic and eloquent cortical areas and gave their consent. The yttrium aluminum perovskite (YAP) laser stimulation paradigm was submitted to, and approved by, the local Ethics Committee. Data from two patients were excluded because paroxysmal epileptic discharges were shown to occur in the recorded cingulate regions. In the other $16 \mathrm{pa}-$ tients, several spontaneous seizures could be recorded during the SEEG, all of which originated in the mesial structures of the temporal lobe. In these patients, ictal discharges propagated outside the mesiotemporal cortex and involved most frequently the temporal pole, the temporal neocortex, and the orbitofrontal cortex.

We explored a total of 36 cingulate and 13 opercular SII sites in nine women and seven men (mean age 29 years, range: $15-47$ years). The LEP recording was performed at the end of the SEEG monitoring period that lasted a maximum of 2 weeks. At the time of the SEEG procedure, antiepileptic treatment had been tapered down, so that all patients were under monotherapy with one of the major antiepileptic drugs (carbamazepine, phenytoin, valproate, lamotrigine, or topiramate) with daily dosages at or slightly under the minimum of their usual therapeutic range.

Electrode implantation. Intracerebral electrodes were implanted using the Talairach's stereotactic frame. As a first step, a cerebral angiography was performed in stereotactic conditions using an $\mathrm{x}$-ray source located $4.85 \mathrm{~m}$ away from the patient's head. This eliminates the linear enlargement caused by $\mathrm{x}$-ray divergence, so that the films could be used for measurements without any correction. In a second step, the relevant targets were identified on the patient's magnetic resonance imaging (MRI), previously enlarged at scale one-to-one. Because MR and angiographic images were at the same scale, they could easily be superimposed, thus minimizing the risk of damage to cerebral vessels during implantation. The electrodes were orthogonally implanted using the Talairach's stereotactic grid; each electrode had 10-15 contacts, each of $2 \mathrm{~mm}$ length, separated by $1.5 \mathrm{~mm}$, and could be left in place chronically up to $15 \mathrm{~d}$. Because of the physical characteristics of the contacts (stainless steel), it was impossible to perform MRI with electrodes in place. Scale 1:1 skull radiographies superimposed to scale 1:1 angiographies were used to perform the implantation within the stereotactic frame of Talairach and Tournoux (1988). The electrode tracks and the contacts of each electrode could be plotted onto the appropriate MRI slices of each patient (MRIcro software) (Rorden and Brett, 2000). Each contact was then localized in the Talairach space using its stereotactic coordinates: $x$ for the lateral medial axis, with $x=0$ being the coordinate of the sagittal interhemispheric plane; $y$ for the rostrocaudal (anterior-posterior) axis, $y=0$ being the coordinate of the vertical anterior commissure (VAC) plane and $z$ for the inferior-superior axis, $z=0$ being the coordinate of the horizontal anterior commissure-posterior commissure (AC-PC) plane (Frot and Mauguière, 1999, 2003; Frot et al., 1999, 2001).

Cingulate cortex exploration. Six patients had a single electrode implanted in the CC, four patients had two, three patients had three, and in two patients, four electrodes explored different subregions of the CC (Table 1). A single patient had five electrodes implanted along the rostrocaudal cingulate axis (patient 2; see Table 1). Altogether, the CC was explored by 36 electrodes distributed along the rostrocaudal axis, from $+36 \mathrm{~mm}$ rostral to $-61 \mathrm{~mm}$ caudal to the VAC plane (Talairach system of stereotactic coordinates), thus covering a large part of CC extending 
from the perigenual region to the posterior retrosplenial CC area (Fig. 1). Two or three contacts per electrode explored the gray matter of the cingulate region; however, only the contact showing the greatest amplitude in each electrode was used to calculate response latency and voltage.

Suprasylvian opercular SII cortex exploration. Thirteen patients of the study had electrodes implanted in the suprasylvian opercular cortex. LEPs were recorded in the parietal operculum at depths between 37 and $56 \mathrm{~mm}$ from midsagittal plane using a total number of 13 electrodes distributed along the rostrocaudal axis between $6 \mathrm{~mm}$ rostral and $20 \mathrm{~mm}$ caudal to the VAC coronal plane (Fig. 2, Table 1). Therefore our recording contacts explored mostly the SII and parietal ventral (PV) somatosensory areas corresponding to cytoarchitectonic OP1 and OP4 areas, respectively (Eickhoff et al., 2006a,b, 2007). According to human fMRI activation studies, the center of mass of the SII-PV cortex is located at a depth between 42 and $53 \mathrm{~mm}$ from midsagittal plane and between 17 and 25 mm caudal to VAC plane along the $y$-axis (for review, see Özcan et al., 2005). The $y$ coordinates of our most rostral contacts corresponded to those of the rostral somatotopic representation $[15.0 \pm 5.4 \mathrm{~mm}(\mathrm{SD})$ caudal to VAC plane], as identified in the parietal operculum by Disbrow et al. (2000).

In what follows, we refer to the parietal opercular region that we explored as "SII" because, as a result of the limited number of recording contacts in each individual patient, it was not possible to assess separately responses from the multiple somatotopic subdivisions of the suprasylvian somatosensory cortex, as individualized by electrophysiological recordings in monkeys and functional imaging in humans. The depth coordinates of what we called "SII" cortex do not overlap with those of the insular cortex $(27<x<36 \mathrm{~mm})$, where we could elicit pain by direct electrical stimulation (Mazzola et al., 2006) and where we have recorded $\mathrm{CO}_{2}$ LEPs peaking $50 \mathrm{~ms}$ later than in SII (Frot and Mauguière, 2003). Furthermore we checked on individual brain MRI that contacts were located in the parietal operculum cortex (SII) and not in the insular cortex.

Among the 13 patients who had electrodes implanted in the suprasylvian opercular cortex, six had also one or several electrodes implanted in the midcingulate gyrus (eight electrodes in total). This group of six patients allowed simultaneous recording and direct comparison of cingulate and opercular responses in the same runs of laser stimulation under identical experimental conditions.

Stimulation procedure, recording, and signal averaging. LEP recordings were performed between 10 and $15 \mathrm{~d}$ after electrode implantation. During the recordings, the patients lay relaxed on a bed in a quiet room. Nociceptive stimuli were applied with a Nd:YAP laser (wavelength 1.34 $\mu \mathrm{m}$, El-En), which delivered brief radiant heat pulses of $5 \mathrm{~ms}$ duration.

The laser beam was transmitted from the generator to the stimulating probe via an optical fiber of $10 \mathrm{~m}$ length. Two separate runs of 12-16 stimulations applied to the skin in the superficial radial nerve territory on the dorsum of the hand were delivered contralaterally and ipsilaterally to the implanted electrodes. The interstimulus interval varied randomly between 10 and $25 \mathrm{~s}$. The laser beam was slightly moved between two successive stimuli to avoid habituation and especially peripheral nociceptor fatigue (Schwarz et al., 2000). The intensity was set up according to subjects' subjective reports, rated on a visual analog scale. The printed scales consisted of $10 \mathrm{~cm}$ horizontal lines where the left extreme was labeled "no sensation" and the right extreme "maximal pain," and an anchored level 4 was at pain threshold. Stimulation intensity was kept stable for any given patient during the whole recording time, $20 \%$ above the pain threshold determined before the experimental session. The sub- jects had to provide pain ratings after each run of stimulation. For all patients, pain threshold was obtained with a beam diameter of $4-5 \mathrm{~mm}$ and beam energy of $1 \mathrm{~J}$, i.e., $50-79 \mathrm{~mJ} / \mathrm{mm}^{2}$. The mean intensity rating was $5.1 \pm 0.9$, described as "painful but tolerable" by all patients.

On-line recordings were performed using a sampling frequency of 256 $\mathrm{Hz}$ and a bandpass filter of $0.03-100 \mathrm{~Hz}$ (Micromed, St. Etienne des Oullières, France) both in bipolar and referential modes. The reference electrode was chosen for each patient on an implanted contact located in the skull.

Epoching of the EEG, selective averaging, and record analysis were performed off-line using Neuroscan software. The continuous EEG was cut into epochs, each epoch beginning $100 \mathrm{~ms}$ before and ending $900 \mathrm{~ms}$ after the stimulus. A $100 \mathrm{~ms}$ prestimulus baseline correction was performed before averaging. Epochs presenting epileptic transient activities were rejected from analysis. Averaging was performed to reduce the background EEG noise so as to facilitate analysis of stimulus-locked activity (evoked potentials). Finally, the two runs of laser stimulation were pooled after having checked that the averaged waveforms were reproducible.

Responses were labeled according to the polarity-latency nomenclature in which the letters $\mathrm{N}$ and $\mathrm{P}$, referring to the negative $(\mathrm{N})$ or positive (P) polarity of the potential, are followed by the mean peak latency in milliseconds. In all figures, negative potentials at the intracortical recording site are represented upward. In the text and tables, mean voltages, latencies, and time intervals are given \pm 1 SD.

\section{Results}

\section{Polarity, latency, and voltage of cingulate LEPs}

Contralateral cingulate LEPs could be recorded exclusively from contacts located in the pMCC (Fig. 1, cluster 3). They were composed of one or two biphasic components (Fig. 3). An early component was observed in 9 of 10 recorded sites in pMCC. It was composed of a negative ${ }_{\mathrm{CC}} \mathrm{N} 120$ wave followed by a positive CC P195 wave (Tables 2, 3). A similar early biphasic component was also recorded when the laser stimulus was delivered ipsilaterally to the implanted electrode. This ipsilateral pMCC response was significantly delayed by $17.9 \pm 6.7 \mathrm{~ms}(t$ tests, $p<0.001)$ and $17.3 \pm 16.7 \mathrm{~ms}(p=0.03)$ with respect to the contralateral 
A

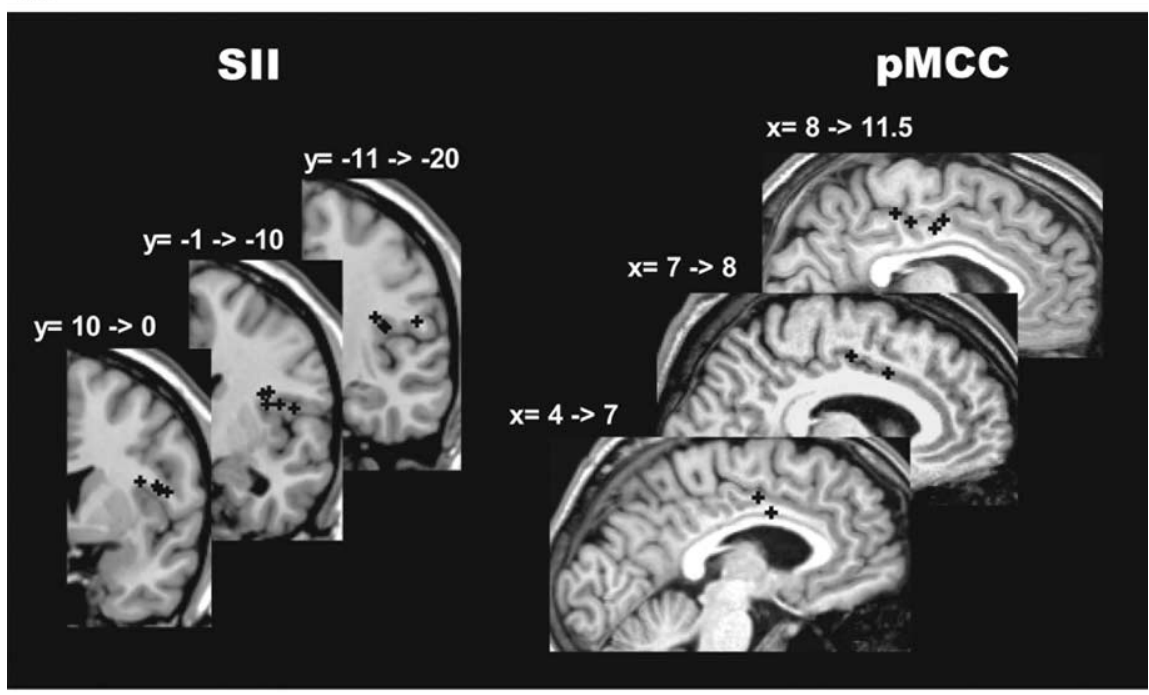

B

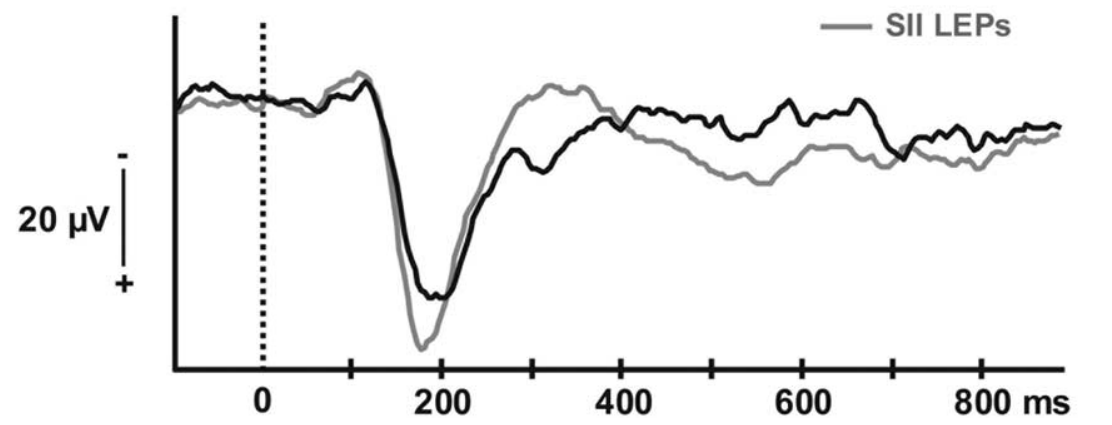

Figure 2. SII versus cingulate LEPs. $\boldsymbol{A}$, Location of the SII and pMCC contacts where the maximal amplitudes of the N/P deflection in bipolar mode were recorded. The contacts were plotted on MRI slices chosen in the pool of the MRI of all patients included in the study, according to their Talairach coordinates. The precise SII and pMCC location of all these contacts was verified by plotting them on the appropriate MRI slices of each patient. $\boldsymbol{B}$, Grand average LEPs in bipolar recording mode from all the patients in SII (gray) and CC (black).

${ }_{\mathrm{CC}} \mathrm{N} 120$ and ${ }_{\mathrm{CC}} \mathrm{P} 195$, respectively (Tables 2, 3, Fig. 4). Latency delays between ipsilateral and contralateral responses were comparable for the early negative and positive peaks ( $t$ test for delay $\left[{ }_{\mathrm{CC}} \mathrm{N} 120_{\text {ipsi }}-{ }_{\mathrm{CC}} \mathrm{N} 120_{\text {contra }}\right]$ versus delay $\left[_{\mathrm{CC}} \mathrm{P} 195_{\mathrm{ipsi}}-\right.$ $\left.{ }_{\mathrm{CC}} \mathrm{P} 195_{\text {contra }}\right] ; p=0.9$ ).

In 6 of the 10 sites recorded in the pMCC, we also observed a later biphasic component made of a negative ${ }_{\mathrm{CC}} \mathrm{N} 235$ wave followed by a positive ${ }_{\mathrm{CC}} \mathrm{P} 275$ wave (Tables 2,3 ). The intervals between the two consecutive negative $\left({ }_{\mathrm{CC}} \mathrm{N} 120{ }_{-}{ }_{\mathrm{CC}} \mathrm{N} 235\right)$ and positive waves ( $\left.{ }_{\mathrm{CC}} \mathrm{P} 195-{ }_{\mathrm{CC}} \mathrm{P} 275\right)$ for contralateral painful stimulation were $111 \pm 37.5 \mathrm{~ms}$ and $77.6 \pm 22.7 \mathrm{~ms}$, respectively. A similar late biphasic component was also recorded when the painful stimulus was delivered ipsilaterally to the implanted electrode. In contrast to the early components, the latency of the late waveform did not differ for ipsilateral or contralateral stimulation ( $t$ test; $p=0.3$ for the ${ }_{\mathrm{CC}} \mathrm{N} 235$ and ${ }_{\mathrm{CC}} \mathrm{P} 275$ ) (Tables 2, 3, Fig. 4). In one patient (Fig. 3, patient 6) the early and the late components of the pMCC LEPs could be recorded separately on two distinct electrode tracks, the earlier component ( ${ }_{\mathrm{CC}} \mathrm{N} 120-$ $\left.{ }_{\mathrm{CC}} \mathrm{P} 195\right)$ being recorded by the more caudally implanted electrode.

No reproducible LEPs were recorded along any of the elec- trodes implanted in the other subregions of the cingulate cortex, rostral or caudal to the pMCC, at least in our experimental conditions (Fig. 1).

\section{Stereotactic localization of the cingulate LEPs}

The cingulate LEPs were recorded by the two or three deepest contacts of the electrodes. When several contacts explored the CC, the contact considered was the one showing the maximal amplitude of the $\mathrm{N} / \mathrm{P}$ deflections. Thus, for any given CC location, only one single contact per electrode track and per subject was used to assess response latency and voltage. We purposely avoided to pool data from all contacts showing similar peaks (Ohara et al., 2004a) because this may significantly blur interregional differences by averaging different latency values in the same individual.

As illustrated in figure 1, LEP recording sites in CC were clustered in five subregions, the stereotactic coordinates of which corresponded to those of the CC subregions individualized by Vogt (Vogt et al., 2003; Vogt, 2005): cluster 1 (eight contacts), ventral posterior cingulate cortex (vPCC); cluster 2 (eight contacts), dorsal posterior cingulate cortex (dPCC); cluster 3 (10 contacts), pMCC; cluster 4 (five contacts), anterior midcingulate cortex (aMCC); and cluster 5 (five contacts), pregenual anterior cingulate cortex (pACC).

The ${ }_{\mathrm{CC}} \mathrm{N} 120-{ }_{\mathrm{CC}} \mathrm{P} 195$ LEPs were recorded along the trajectory of the electrodes penetrating the cingulate cortex at the level of the pMCC (Fig. 1). The cortical volume where pMCC LEPs were recorded was bounded by vertical planes $+6 \mathrm{~mm}$ anterior and $-28 \mathrm{~mm}$ posterior to the VAC coronal plane ( $y$ coordinates) and between horizontal planes +28 and $+48 \mathrm{~mm}$ above the horizontal AC-PC plane ( $z$ coordinates). These responses were picked up with maximal amplitude on contacts located between 6.7 and $11.2 \mathrm{~mm}$ from the midsagittal vertical plane ( $x$ coordinates) (Table 1, Fig. 3 ).

The late ${ }_{\mathrm{CC}} \mathrm{N} 235-{ }_{\mathrm{CC}} \mathrm{P} 275$ cingulate components were recorded in the same cingulate area, i.e., the pMCC (Fig. 1). In contrast to the early ones, the late cingulate components were not recorded along all the electrodes penetrating the pMCC. They were recorded in the more posterior $(-28 \mathrm{~mm}<y<-20 \mathrm{~mm})$ and more anterior $(-2 \mathrm{~mm}<y<+6 \mathrm{~mm})$ contacts located in the pMCC, but not on the contacts located between -18 and -9 $\mathrm{mm}$ from the VAC coronal plane.

\section{Stereotactic localization of the SII LEPs}

The SII LEPs were recorded along the trajectory of all electrodes penetrating the SII cortex between vertical planes $6 \mathrm{~mm}$ anterior and $-20 \mathrm{~mm}$ posterior ( $y$ coordinates) to the VAC plane, and horizontal planes 10 and $21 \mathrm{~mm}$ above ( $z$ coordinates) the horizontal AC-PC plane. The selection procedure of contacts used for latency and voltage measurements was the same as that described 

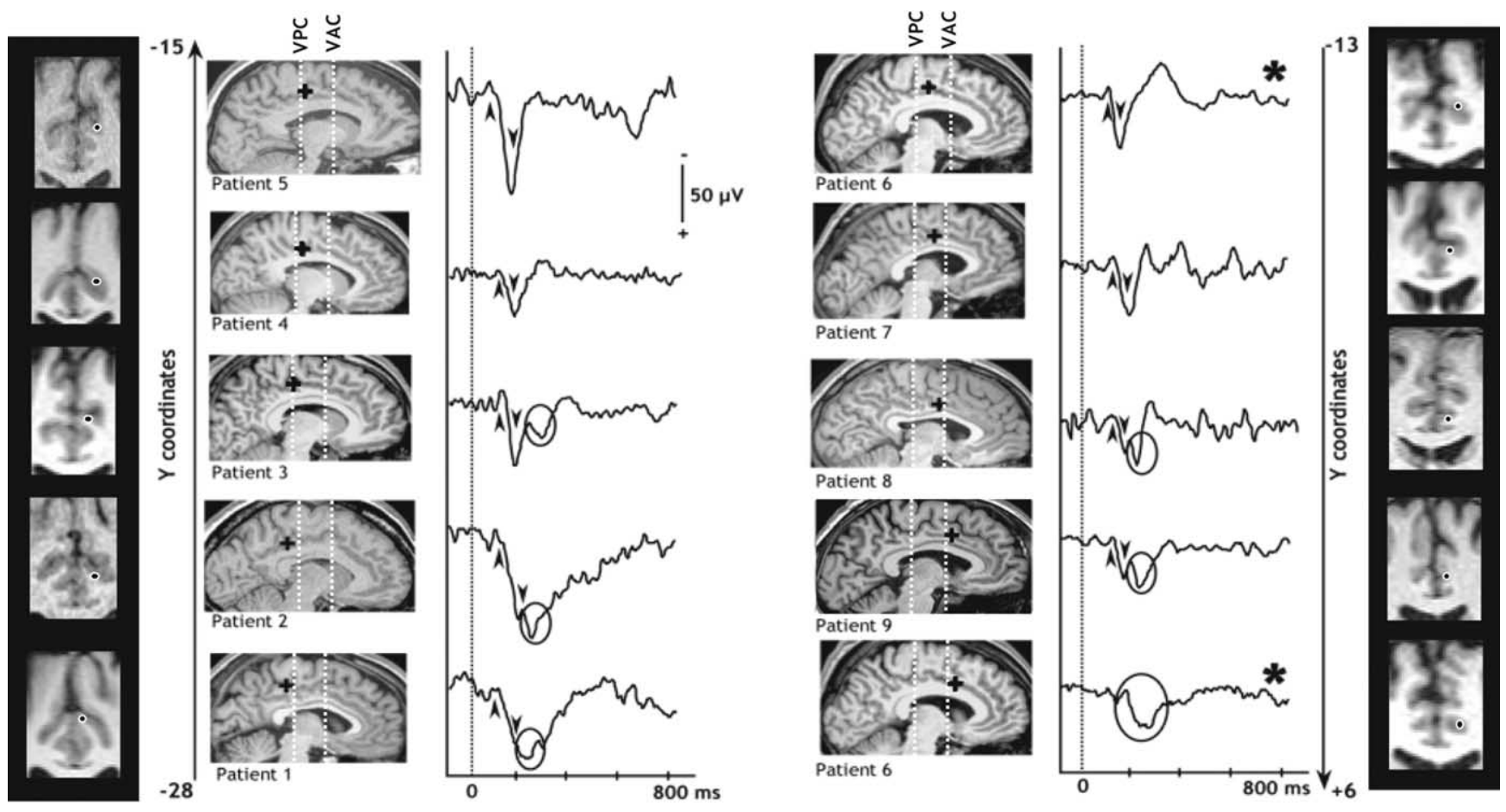

Figure 3. LEPs recorded in the PMCC and location of the contacts. Evoked responses recorded in the pMCC cluster (see Fig. 1) in nine patients. The location of the contacts (black dots and black crosses) presenting such responses were plotted on sagittal and coronal MRI slices of each patient. The more posterior location is situated in the bottom left corner of the figure, and the more anterior location is situated in the bottom right corner. An early CC LEP component was recorded in all patients (black arrows) on contacts located between vertical planes $+6 \mathrm{~mm}$ anterior and $-28 \mathrm{~mm}$ posterior to the VAC coronal plane ( $y$ coordinates). We also recorded a late CC LEP component (in black circles) in six patients on the more posterior $(-28 \mathrm{~mm}<y<-20 \mathrm{~mm}$ ) and more anterior $(-2 \mathrm{~mm}<y<+6 \mathrm{~mm})$ contacts within the $\mathrm{pMCC}$, but not on the contacts located between -18 and $-9 \mathrm{~mm}$ from the VAC coronal plane. In one patient, early and late components of the CC LEPs were separately recorded on two distinct electrode tracks (patient 6, black star). VPC, Vertical posterior commissure plane

Table 2. Latencies of cingulate responses

\begin{tabular}{|c|c|c|c|c|c|c|c|c|}
\hline & \multicolumn{8}{|c|}{ Latencies (ms) } \\
\hline & \multicolumn{4}{|c|}{ Contralateral } & \multicolumn{4}{|c|}{ Ipsilateral } \\
\hline & ${ }_{C \mathrm{~N}} \mathrm{~N} 120$ & ${ }_{C \mathrm{C}} \mathrm{P} 195$ & ${ }_{\mathrm{C}} \mathrm{N} 235$ & ${ }_{C \mathrm{C}} \mathrm{P} 275$ & ${ }_{C \mathrm{C}} \mathrm{N} 120$ & ${ }_{\text {तCP195 }}$ & ${ }_{C \mathrm{C}} \mathrm{N} 235$ & ${ }_{{ }_{C}} \mathrm{P} 275$ \\
\hline Mean & 119.3 & 193.1 & 232.7 & 273.9 & 133.4 & 205.4 & 221.1 & 258.6 \\
\hline SE & 5.04 & 9.3 & 13.8 & 10.5 & 5.1 & 3.4 & 8.9 & 10.6 \\
\hline
\end{tabular}

Table 3. Amplitudes of cingulate responses

\begin{tabular}{|c|c|c|c|c|}
\hline & \multicolumn{4}{|l|}{ Amplitudes $(\mu \mathrm{V})$} \\
\hline & \multicolumn{2}{|l|}{ Contralateral } & \multicolumn{2}{|l|}{ Ipsilateral } \\
\hline & ${ }_{C C} \mathrm{~N} 120-{ }_{C C} \mathrm{P} 195$ & ${ }_{{ }_{C C} \mathrm{~N} 235-}{ }_{C \mathrm{C}} \mathrm{P} 275$ & ${ }_{C C} \mathrm{~N} 120-{ }_{C C} \mathrm{P} 195$ & ${ }_{{ }_{C C}} \mathrm{~N} 235-{ }_{C C} \mathrm{P} 275$ \\
\hline Mean & 50.3 (for $\mathrm{N} 120:-4.7$ ) & 17.2 & 55.1 (for $\mathrm{N} 120:-7$ ) & 19.4 \\
\hline SE & $7.2\left(\right.$ for $\left.{ }_{C C} \mathrm{~N} 120: 1.5\right)$ & 3.2 & 10.1 (for $\left.{ }_{C \mathrm{C}} \mathrm{N} 120: 2.7\right)$ & 6.4 \\
\hline
\end{tabular}

above for CC LEPs. These responses were picked up with maximal amplitude on contacts located between 36.7 and $55.7 \mathrm{~mm}$ from the midsagittal vertical plane ( $x$ coordinates) (Table 1, Fig. 2 ).

\section{Cingulate versus SII LEPs}

LEPs contralateral to the stimulation site were recorded along all the electrode tracks located in SII. They consisted of a negative wave $\left({ }_{\mathrm{SII}} \mathrm{N} 120\right)$ followed by a positive one $\left({ }_{\mathrm{SII}} \mathrm{P} 180\right)$ (Fig. 2$)$, latencies and voltages of which are given in Tables 4 and 5. A similar biphasic component was also recorded when the laser painful stimulus was ipsilateral to the implanted electrode, but such ipsilateral responses peaked $16.4 \pm 7 \mathrm{~ms}\left({ }_{\mathrm{SII}} \mathrm{N} 120 ; t\right.$ tests, $\left.p<0.001\right)$ and $16.8 \pm 13.3 \mathrm{~ms}\left({ }_{\mathrm{SII}} \mathrm{P} 180 ; t\right.$ test, $\left.p=0.04\right)$ later than the contralateral ones (Tables 4, 5). Latency delays between ipsilateral and contralateral responses were comparable for the negative and positive peaks ( $t$ test for delay $\left[{ }_{\mathrm{SII}} \mathrm{N} 120_{\text {ipsi }}-{ }_{\mathrm{SII}} \mathrm{N} 120_{\text {contra }}\right]$ versus delay $\left.\left[{ }_{\text {SII }} \mathrm{P} 180_{\text {ipsi }}-{ }_{\text {SII }} \mathrm{P} 180_{\text {contra }}\right] ; p=0.9\right)$.

The latencies of the SII response and of the early biphasic component of cingulate LEPs did not significantly differ ( $t$ tests; for ${ }_{\text {SII }} \mathrm{N} 120$ versus ${ }_{\mathrm{CC}} \mathrm{N} 120, p=0.85$; for ${ }_{\mathrm{SII}} \mathrm{P} 180$ versus ${ }_{\mathrm{CC}} \mathrm{P} 195, p=0.21$ ) (Fig. 2). In contrast, the negative and positive peaks of the SII responses occurred $116.4 \pm 13.3 \mathrm{~ms}$ ( $t$ tests, $p=0.002)$ and $98.4 \pm 26.84 \mathrm{~ms}(p=0.001)$ earlier than the late ${ }_{\mathrm{CC}} \mathrm{N} 235$ and ${ }_{\mathrm{CC}} \mathrm{P} 275$ cingulate peaks, respectively. These latency delays between the SII response and the late component of the cingulate response were not significantly different for negative and positive peaks ( $t$ test for delay $\left[{ }_{S I I} \mathrm{~N} 120-{ }_{C C} \mathrm{~N} 235\right]$ versus delay $\left.\left[{ }_{\mathrm{SII}} \mathrm{P} 180-{ }_{\mathrm{CC}} \mathrm{P} 275\right] ; p=0.3\right)$.

\section{Discussion}

Two main findings are revealed by our study. First, only a restricted area in the MCC region (the pMCC) responds to painful 


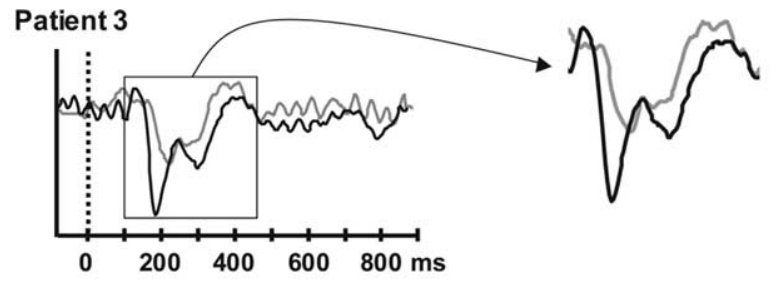

Patient 9

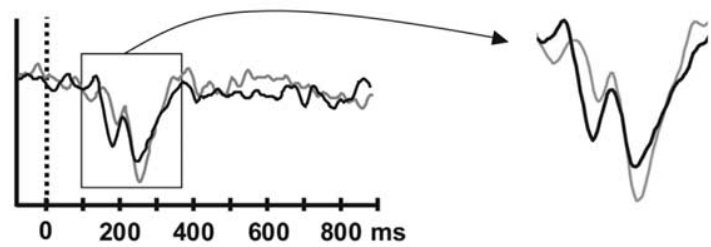

Patient 6

contro

ipsi
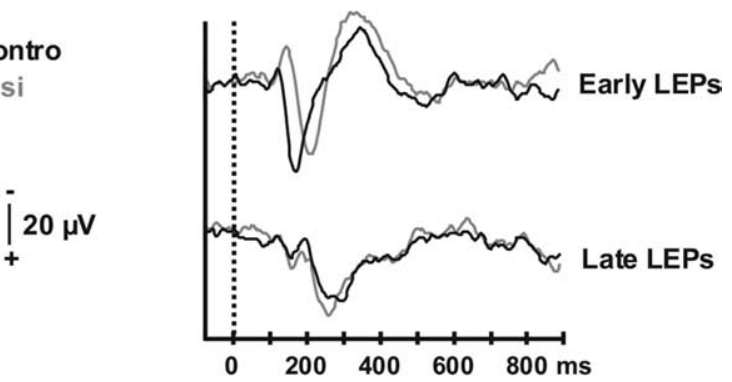

Figure 4. Contralateral versus ipsilateral CCLEPs. Cortical cingulate responses evoked by YAP laser stimuli recorded contralateral (black traces) and ipsilateral (gray traces) to the stimulated hand in three patients. Early and late components of CC LEPs were recorded on the same contacts for patients 3 and 9 and on two different contacts for patient 6 . Early ipsilateral LEPs peak $\sim 17$ ms later than their contralateral homologues, whereas there was no latency difference between contralateral and ipsilateral late CC LEPs.

Table 4. Latencies of SII responses

\begin{tabular}{|c|c|c|c|c|}
\hline & Latencie & & & \\
\hline & Contrala & & Ipsilater & \\
\hline & sII $\mathrm{N} 120$ & ${ }_{s \|} \mathrm{P} 180$ & sII $\mathrm{N} 120$ & ${ }_{\mathrm{SII}} \mathrm{P} 180$ \\
\hline Mean & 119 & 178.9 & 128.9 & 194.2 \\
\hline SE & 6.3 & 6.03 & 5.9 & 10.1 \\
\hline
\end{tabular}

Table 5. Amplitudes of SII responses

\begin{tabular}{|c|c|c|}
\hline \multirow{3}{*}{ 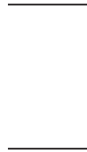 } & \multicolumn{2}{|l|}{ Amplitudes $(\mu \mathrm{V})$} \\
\hline & Contralateral & Ipsilateral \\
\hline & ${ }_{\mathrm{SII}} \mathrm{N} 120-{ }_{\mathrm{SII}} \mathrm{P} 180$ & ${ }_{s \| 1} \mathrm{~N} 120-{ }_{s \| l} \mathrm{P} 180$ \\
\hline Mean & 34.6 & 28.2 \\
\hline SE & 6.7 & 7.1 \\
\hline
\end{tabular}

laser stimulation in a poststimulus time window of $900 \mathrm{~ms}$. Second, cingulate LEPs show two components, of which the earlier one peaks at latencies similar to those of SII LEPs.

Because of the nature of the laser stimulus and of our experimental conditions, our findings do not imply that the pMCC is the only part of the CC to be involved in pain cortical processing. Indeed, functional imaging studies have shown pain-related cingulate activities in slightly more anterior regions, and even in the perigenual cingulate when the stimulus was strongly unpleasant (Lorenz and Casey, 2005). However, emotional and vegetative reactions involving the rostral-perigenual CC are not likely to be triggered by our laser stimulus, which produces a sharp pinprick sensation qualified as "painful," but seldom perceived as strongly unpleasant or hyperalgesic. In accordance with this view, Lenz et al. (1998) using laser stimulation and subdural electrodes recorded local maxima of CC LEPs $30 \mathrm{~mm}$ anterior to the central sulcus, i.e., over the MCC, and not in regions rostral or caudal to this area.

\section{Response localization}

The location of the pMCC responses is consistent with that of CC sources identified by dipolar modeling of scalp LEPs (Tarkka and Treede, 1993; Valeriani et al., 1996) (for review, see Garcia-Larrea et al., 2003). However, modeled MCC dipoles are most often reported to peak at 220-340 ms (N2-P2 LEPs), i.e., at latencies consistent with the late intracortical response that we identified in six of our nine patients. The reasons why the early pMCC activities may not be easily individualized by source modeling of scalp recordings are multiple: (1) a low-pass filter effect of skull, corticospinal fluid, and meninges that tends to lump together multiple sources with similar location (Nunez and Srinivasan, 2005); (2) an orientation of the early pMCC LEP dipolar source that may render this component difficult to record by surface (or even subdural) electrodes; (3) the contribution of other sources in the building of the scalp LEPs including the posterior parietal, amygdalohippocampal, and/or anterior insular regions (Valeriani et al., 1996; Cruccu et al., 2003). Notwithstanding such difficulties, Schlereth et al. (2003) were able to model early LEP cingulate sources in the pMCC peaking only $50 \mathrm{~ms}$ later than the intracortical activities reported here. Also, if one considers the activity onset of modeled CC sources, rather that their peaking latency, the discrepancy between scalp and intracortical recordings is less pronounced. Thus, dipolar source activity has been reported to begin as early as $130-150 \mathrm{~ms}$ poststimulus (Tarkka and Treede, 1993; Valeriani et al., 1996), suggesting that source modeling tends to lump together the two consecutive cingulate responses reported in the present study.

Subdural cortical recordings in epileptic patients have yielded important but somewhat variable results. Whereas Lenz et al. (1998) and Rios et al. (1999) reported only "late" cingulate responses at 220-250 ms, Ohara et al. (2004a,b) recorded more recently a negative wave at $140-160 \mathrm{~ms}$, i.e., at latencies close to those obtained in our patients. The peak latencies of opercular and CC responses were almost identical in one patient and delayed by $10-15 \mathrm{~ms}$ in two. Although such differences were not statistically significant, they were similar to the $17 \mathrm{~ms}$ lag we measured between pMCC LEPs contralateral and ipsilateral to the stimulus, and thus compatible with synaptic transmission between the suprasylvian and cingulate cortex. By providing direct intracortical recordings, our study shows that the pMCC and the SII areas respond simultaneously to noxious A- $\delta$ fibers inputs, thus suggesting that pMCC processes pain inputs in parallel with the suprasylvian opercular cortex.

\section{Anatomical pathways supporting the pain cingulate responses}

In monkeys, the MCC receives fibers from the intralaminar thalamic nuclei, especially the central lateral and centromedianparafascicular complex (Baleydier and Mauguière, 1980; Hatanaka et al., 2003; Vogt et al., 2005). A number of spinothalamic tract neurons, with small receptive fields and soma situated in 
layers I and V of the dorsal horn, send bifurcated axons to lateral and medial thalamic nuclei (Willis and Westlund, 1997; Weiss et al., 2005), and thus indirectly to both medial (CC) and lateral (SII) cortical areas. These neurons could provide a neuroanatomical support of early pMCC responses developing in parallel with SII LEPs.

The long delay $(\sim 100 \mathrm{~ms})$ between the early and the late pMCC responses suggests that the latter are unlikely to be generated by monosynaptic transmission from the early pMCC response generator. Whereas early responses exhibit a $16-18 \mathrm{~ms}$ interhemispheric delay, compatible with callosal interhemispheric transfer, late pMCC responses develop simultaneously in both hemispheres, suggesting that the early and late pMCC LEPs are triggered by inputs transmitted through two distinct pathways. This duality of cingulate responses is consistent with recent data showing that the late portion of the scalp LEP disappears during sleep, leaving an early component with latency similar to that of the early pMCC response (Bastuji et al., 2008).

The late pMCC LEPs can be triggered either through corticocortical projections or by thalamocingulate inputs reaching in parallel the contralateral and ipsilateral pMCC. This latter hypothesis implies a bilateral thalamic projection of spinothalamic fibers, which, although scarce, has been substantiated (Willis et al., 1979; Apkarian and Hodge, 1989). The important delay observed between the early and late pMCC responses suggests that the latter should depend on a much slower conducting system, but the hypothesis of a dependence on C-fiber activation is incompatible with its latency (Mouraux et al., 2004). Although the range for $\mathrm{A}-\delta$ conduction velocity is very wide $(7-30 \mathrm{~m} / \mathrm{s}$ ) (Adriaensen et al., 1983; Naka and Kakigi, 1998), and different subpopulations of fibers might have selective connections with the spinothalamic neurons (for review, see Wolf, 1994), the $100 \mathrm{~ms}$ latency difference between early and late pMCC LEPs would imply differences in transmission time hardly compatible with the spectrum of $\mathrm{A}-\delta$ conduction velocities. Alternatively, the late pMCC response may reflect an integrative response to inputs reaching the pMCC through multisynaptic corticocortical connections from both sensory and associative areas. Indeed, the pMCC receives inputs from multiple cortical sources, including other subregions of CC, posterior parietal cortex, insula, amygdala, and motor and premotor cortices, and sends back projections to most of them (Baleydier and Mauguière, 1980; Morecraft and Van Hoesen, 1992, 1993, 1998; Hatanaka et al., 2003; Morecraft et al., 2007).

\section{Functional significance}

The finding of a short-latency response of pMCC to pain input, concomitant to SII LEPs, suggests that this area may participate in attention capture and orientation toward painful stimuli (Peyron et al., 1999; Tölle et al., 1999). It is unlikely that cingulate responses may participate in the precise sensory encoding of stimulus features, given the poor intensity coding properties and very large receptive fields of CC neurons (Casey, 1966; Dong et al., 1978; Sikes and Vogt, 1992; Yamamura et al., 1996) and the reported fact that pain cannot be localized despite preserved CC if the lateral somatosensory areas are destroyed (Ploner et al., 1999). Moreover, electrical microelectrode stimulation at pMCC sites where pain-sensitive neurons were recorded does not elicit pain sensations (Hutchinson et al., 1999). Conversely, one can assume that if pMCC participates in control of limb withdrawal away from the pain stimulus, it has to be operational at very short latencies, without the need for prior sequential processing through other cortical areas. In support of this, the location of
LEPs recorded in this study is coherent with that of the so-called "motor CC" (Picard and Strick, 1996; Büchel et al., 2002; Hatanaka et al., 2003), which contains two separate areas projecting to spinal cord and motor cortex (Dum and Strick, 1991; Morecraft and Van Hoesen, 1992) and is involved in motor output and preparation for voluntary movement (Fink et al., 1997; Picard and Strick, 2001; Cunnington et al., 2003; Niddam et al., 2005). This region is also connected with pre-SMA and SMA (Hatanaka et al., 2003), which participate in control of action and withdrawal reactions (Nachev et al., 2007), and with more rostral cingulate cortex (Vogt and Pandya, 1987), involved in cognitive functions and emotions (MacDonald et al., 2000; Vogt, 2005). It is noticeable that no LEPs were recorded in these rostral CC areas, suggesting that our laser stimulus was not strong/unpleasant enough to trigger any response, or that the evoked activity was not phase-locked enough to the stimulus to be identifiable after averaging.

\section{Conclusions}

Our electrophysiological data provide direct evidence in humans that earliest activity in the "medial" and "lateral" pain systems for pain processing occurs simultaneously, at least to painful stimuli with sharp, A- $\delta$-like, characteristics. The short-latency pMCC responses to pain indicate that, contrary to previous assumptions, the "medial pain system" is not devoted exclusively to the slow processing of cognitive and emotional information, but is also involved in very fast information processing subserving attentional orienting and motor withdrawal. These functions are, not surprisingly, conducted in parallel with the stimulus appraisal initiated by the sensory-discriminative "lateral" pain system.

\section{References}

Adriaensen H, Gybels J, Handwerker HO, Van Hees J (1983) Response properties of thin myelinated (A-delta) fibers in human skin nerves. J Neurophysiol 49:111-122.

Albe-Fessard D, Berkley KJ, Kruger L, Ralston III HJ, Willis Jr WD (1985) Diencephalic mechanisms of pain sensation. Brain Res 356:217-296.

Apkarian VA, Hodge CJ (1989) Primate spinothalamic pathways: I. A quantitative study of the cells of origin of the spinothalamic pathway. J Comp Neurol 288:447-473.

Baleydier C, Mauguière F (1980) The duality of the cingulate gyrus in monkey-neuroanatomical study and functional hypothesis. Brain 103:525-554.

Bastuji H, Perchet C, Legrain V, Montes C, Garcia-Larrea L (2008) Laser evoked responses to painful stimulation persist during sleep and predict subsequent arousals. Pain, in press.

Bromm B (2004) The involvement of the posterior cingulate gyrus in phasic pain processing of humans. Neurosci Lett 361:245-249.

Büchel C, Bornhovd K, Quante M, Glauche V, Bromm B, Weiller C (2002) Dissociable neural responses related to pain intensity, stimulus intensity, and stimulus awareness within the anterior cingulate cortex: a parametric single-trial laser functional magnetic resonance imaging study. J Neurosci 22:970-976.

Casey KL (1966) Unit analysis of nociceptive mechanisms in the thalamus of the awake squirrel monkey. J Neurophysiol 29:727-750.

Cruccu G, Pennisi E, Truini A, Iannetti GD, Romaniello A, Le Pera D, De Armas L, Leandri M, Manfredi M, Valeriani M (2003) Unmyelinated trigeminal pathways as assessed by laser stimuli in humans. Brain 126:2246-2256.

Cunnington R, Windischberger C, Deecke L, Moser E (2003) The preparation and readiness for voluntary movement: a high-field event-related fMRI study of the Bereitschafts-BOLD response. NeuroImage 20:404-412.

Disbrow E, Roberts T, Krubitzer L (2000) Somatotopic organization of cortical fields in the lateral sulcus of homo sapiens: evidence for SII and PV. J Comp Neurol 418:1-21.

Dong WK, Ryu H, Wagman IH (1978) Nociceptive responses of neurons in 
medial thalamus and their relationship to spinothalamic pathways. J Neurophysiol 41:1592-1613.

Dum RP, Strick PL (1991) The origin of corticospinal projections from the premotor areas in the frontal lobe. J Neurosci 11:667-689.

Eickhoff SB, Schleicher A, Zilles K, Amunts K (2006a) The human parietal operculum. I. Cytoarchitectonic mapping of subdivisions. Cereb Cortex 16:254-267.

Eickhoff SB, Amunts K, Mohlberg H, Zilles K (2006b) The human parietal operculum. II Stereotaxic maps and correlations with functional imaging results. Cereb Cortex 16:268-279.

Eickhoff SB, Greftkes C, Zilles K, Fink JR (2007) The somatotopic organization of cytoarchitectonic areas on the human parietal operculum. Cereb Cortex 17:1800-1811.

Fink GR, Frackowiak RSJ, Pietrzyk U, Passingham RE (1997) Multiple nonprimary motor areas in the human cortex. J Neurophysiol 77:2164-2174.

Foltz EL, White Jr LE (1962) Pain "relief" by frontal cingulumotomy. J Neurosurg 19:89-100.

Frot M, Mauguière F (1999) Timing and spatial distribution of somatosensory responses recorded in the upper bank of the sylvian fissure (SII area) in humans. Cereb Cortex 9:854-863.

Frot M, Mauguière F (2003) Dual representation of pain in the operculoinsular cortex in humans. Brain 126:1-13.

Frot M, Rambaud L, Guénot M, Mauguière F (1999) Intracortical recordings of early pain-related $\mathrm{CO}_{2}$ laser evoked potentials in the human second somatosensory (SII) area. Clin Neurophysiol 110:133-145.

Frot M, Garcia-Larrea L, Guénot M, Mauguière F (2001) Responses of the supra-sylvian (SII) cortex in humans to painful and innocuous stimuli. A study using intra-cerebral recordings. Pain 94:65-73.

Garcia-Larrea L, Frot M, Valeriani M (2003) Brain generators of laserevoked potentials: from dipoles to functional significance. Neurophysiol Clin 33:279-292.

Hatanaka N, Tokunu H, Hamada I, Inase M, Ito Y, Imanishi M, Hasegawa N, Akazawa T, Nambu A, Takada M (2003) Thalamocortical and intracortical connections of monkey cingulate motor areas. J Comp Neurol 462:121-138.

Hofbauer RK, Rainville P, Duncan GH, Bushnell MC (2001) Cortical representation of the sensory dimension of pain. J Neurophysiol 86:402-411.

Hutchinson WD, Davis KD, Lozano AM, Tasker RR, Dostrovsky JO (1999) Pain-related neurons in the human cingulate cortex. Nat Neurosci 2:403-405.

Isnard J, Guénot M, Ostrowsky K, Sindou M, Mauguière F (2000) The role of the insular cortex in temporal lobe epilepsy. Ann Neurol 48:614-623.

Isnard J, Guénot M, Sindou M, Mauguière F (2004) Clinical manifestations of insular lobe seizures: a stereo-electroencephalographic study. Epilepsia 45:1079-1090.

Jones AK, Kulkarni B, Derbyshire SW (2002) Functional imaging of pain perception. Curr Rheumatol Rep 4:329-333.

Kulkarni B, Bentley DE, Elliott R, Youell P, Watson A, Derbyshire SWG, Frackowiak RSJ, Friston KJ, Jones AKP (2005) Attention to pain localization and unpleasantness discriminates the functions of the medial and lateral pain systems. Eur J Neurosci 21:3133-3142.

Lenz FA, Rios M, Zirh A, Chau D, Krauss G, Lesser RP (1998) Painful stimuli evoke potentials recorded over the human anterior cingulate gyrus. J Neurophysiol 79:2231-2234.

Lorenz J, Casey KL (2005) Imaging of acute versus pathological pain in humans. Eur J Pain 9:163-165.

MacDonald III AW, Cohen JD, Stenger VA, Carter CS (2000) Dissociating the role of the dorsolateral prefrontal and anterior cingulate cortex in cognitive control. Science 288:1835-1838.

Mazzola L, Isnard J, Mauguière F (2006) Somatosensory and pain responses to stimulation of the second somatosensory area (SII) in humans. A comparison with SI and insular responses. Cereb Cortex 16:960-968.

Morecraft RJ, Van Hoesen GW (1992) Cingulate input to the primary and supplementary motor cortices in the rhesus monkey: evidence for somatotopy in areas 24c and 23c. J Comp Neurol 322:471-489.

Morecraft RJ, Van Hoesen GW (1993) Frontal granular cortex input to the cingulate (M3), supplementary (M2) and primary (M1) motor cortices in the rhesus monkey. J Comp Neurol 337:669-689.

Morecraft RJ, Van Hoesen GW (1998) Convergence of limbic input to the cingulate motor cortex in the rhesus monkey. Brain Res Bull 45:209-232.

Morecraft RJ, McNeal DW, Stilwell-Morecraft KS, Gedney M, Ge J, Schroeder CM, Van Hoesen GW (2007) Amygdala interconnections with the cingulate motor cortex in the rhesus monkey. J Comp Neurol 500:134-165.

Mouraux A, Guérit JM, Plaghki L (2004) Refractoriness cannot explain why C-fiber laser-evoked brain potentials are recorded only if concomitant Adelta-fiber activation is avoided. Pain 112:16-26.

Nachev P, Wydell H, O'Neill K, Husain M, Kennard C (2007) The role of the pre-supplementary motor area in the control of action. NeuroImage 36:T155-T163.

Naka D, Kakigi R (1998) Simple and novel method for measuring conduction velocity of A delta fibers in humans. J Clin Neurophysiol 15:150-153.

Niddam DM, Chen L-F, Wu Y-T, Hsieh J-C (2005) Spatiotemporal brain dynamics in response to muscle stimulation. NeuroImage 25:942-951.

Nunez PL, Srinivasan R (2005) Electric fields of the brain-the neurophysics of EEG, Ed 2. Oxford: Oxford UP.

Ohara S, Crone NE, Weiss N, Treede RD, Lenz FA (2004a) Cutaneous painful laser stimuli evoke responses recorded directly from primary somatosensory cortex in awake humans. J Neurophysiol 91:2734-2746.

Ohara S, Crone NE, Weiss N, Treede RD, Lenz FA (2004b) Amplitudes of laser evoked potential recorded from primary somatosensory, parasylvian and medial frontal cortex are graded with stimulus intensity. Pain 110:318-328.

Ostrowsky K, Magnin M, Ryvlin P, Isnard J, Guénot M, Mauguière F (2002) Representation of pain and somatic sensation in the human insula: a study of responses to direct electrical cortical stimulation. Cereb Cortex 12:376-385.

Özcan M, Baumgärtner U, Vucurevic G, Toeler P, Treede RD (2005) Spatial resolution of fMRI in the human parasylvian cortex: comparison of somatosensory and auditory activation. NeuroImage 25:877-887.

Peyron R, Garcia-Larrea L, Grégoire MC, Costes N, Convers F, Lavenne F, Mauguière F, Michel D, Laurent B (1999) Haemodynamic brain responses to acute pain in humans: sensory and attentional networks. Brain 122:1765-1779.

Peyron R, Laurent B, Garcia-Larrea L (2000) Functional imaging of brain responses to pain. A review and meta-analysis. Neurophysiol Clin 30:263-288.

Picard N, Strick PL (1996) Motor areas of the medial wall: a review of their location and functional activation. Cereb Cortex 6:342-353.

Picard N, Strick PL (2001) Imaging the premotor areas. Curr Opin Neurobiol 11:663-672.

Ploner M, Freund HJ, Schnitzler A (1999) Pain affect without pain sensation in a patient with a postcentral lesion. Pain 81:211-214.

Ploner M, Gross J, Timmermann L, Schnitzler A (2002) Cortical representation of first and second pain sensation in humans. Proc Natl Acad Sci USA 99:12444-12448.

Rainville P, Duncan GH, Price DD, Carrier B, Bushnell MC (1997) Pain affect encoded in human anterior cingulate but not somatosensory cortex. Science 277:968-971.

Rios M, Treede R, Lee J, Lenz FA (1999) Direct evidence of nociceptive input to human anterior cingulate gyrus and parasylvian cortex. Curr Rev Pain 3:256-264.

Rorden C, Brett M (2000) Stereotaxic display of brain lesions. Behav Neurol 12:191-200.

Schwarz S, Greffrath W, Büsselberg D, Treede R-D (2000) Inactivation and tachyphylaxis of heat-evoked inward currents in nociceptive primary sensory neurons of rats. J Physiol (Lond) 528:539-549.

Schlereth T, Baumgärtner U, Magerl W, Stoeter P, Treede RD (2003) Lefthemisphere dominance in early nociceptive processing in the human parasylvian cortex. NeuroImage 20:441-454.

Sikes RW, Vogt BA (1992) Nociceptive neurons in area 24 of rabbit cingulate cortex. J Neurophysiol 68:1720-1732.

Talairach J and Tournoux P (1988) Co-planar stereotaxic atlas of the human brain. 3-Dimensional proportional system: an approach to cerebral imaging. Stuttgart: Georg Thieme Verlag.

Tarkka IM, Treede RD (1993) Equivalent electrical source analysis of painrelated somatosensory evoked potentials elicited by a CO2 laser. J Clin Neurophysiol 10:513-519.

Tölle TR, Kaufmann T, Siessmeier T, Lautenbacher S, Berthele A, Munz F, Zieglgansberger W, Willoch F, Schwaiger M, Conrad B, Bartenstein P (1999) Region-specific encoding of sensory and affective components of pain in the human brain: a positron emission tomography correlation analysis. Ann Neurol 45:40-47. 
Valeriani M, Rambaud L, Mauguière F (1996) Scalp topography and dipolar source modeling of potentials evoked by $\mathrm{CO} 2$ laser stimulation of the hand. Electroencephalogr Clin Neurophysiol 100:343-353.

Vogt BA (2005) Pain and emotion intercations in subregions of the cingulate gyrus. Nat Rev Neurosci 6:533-544.

Vogt BA, Pandya DN (1987) Cingulate cortex of the rhesus monkey: II. Cortical afferents. J Comp Neurol 262:271-289.

Vogt BA, Sikes RW, Vogt LJ (1993) In: Neurobiology of cingulate cortex and limbic thalamus (Vogt BA, Gabriel M, eds), pp 19-70, 313-344. Boston: Birkhäuser.

Vogt BA, Berger GR, Derbyshire SWG (2003) Structural and functional dichotomy of human midcingulate cortex. Eur J Neurosci 18:3134-3144.

Weiss N, Lawson HC, Greenspan JD, Ohara S, Lenz FA (2005) Studies of the human ascending pain pathways. Thalamus and Related Systems 3:71-86.

Willis WD, Westlund KN (1997) Neuroanatomy of the pain system and of the pathways that modulate pain. J Clin Neurophysiol 14:2-31.

Willis WD, Kenshalo DR, Leonard RB (1979) The cells of origin of the primate spinothalamic tract. J Comp Neurol 188:543-574.

Woolf CJ (1994) The dorsal horn: state-dependent sensory processing and the generation of pain. In: Textbook of pain, Ed 3 (Wall PD, Melzack R, eds), pp 101-128. Edinburgh: Churchill Livingstone.

Yamamura H, Iwata K, Tsuboi Y, Toda K, Kitajima K, Shimizu N, Nomura H, Hibiya J, Fujita S, Sumino R (1996) Morphological and electrophysiological properties of ACCx nociceptive neurons in rats. Brain Res 735:8392. 